M. Nivat, C. Rattray, T. Rus and G. Scollo (Eds.)

\title{
Algebraic Methodology and Software Technology (AMAST'93)
}

Proceedings of the Third International Conference on Algebraic Methodology and Software Technology, University of Twente, Enschede, The Netherlands 21-25 June 1993

Published in collaboration with the British Computer Society
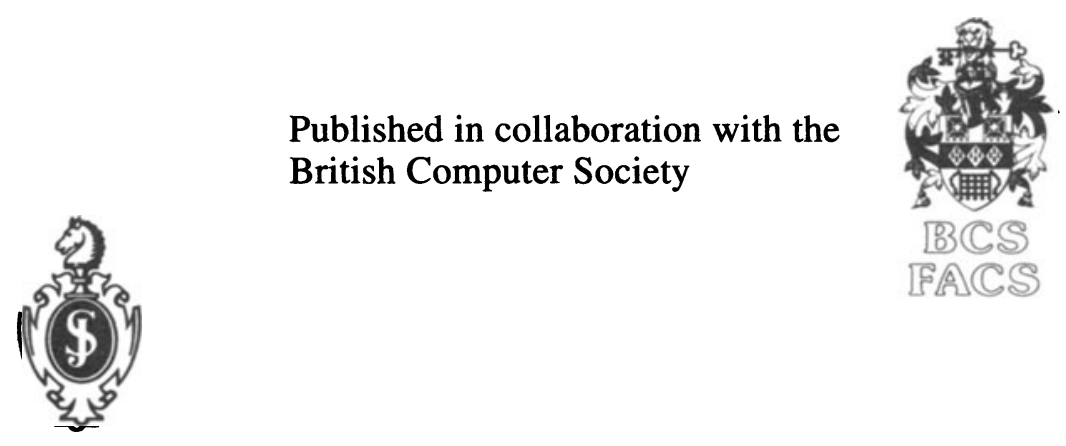

Springer-Verlag

London Berlin Heidelberg New York

Paris Tokyo Hong Kong

Barcelona Budapest 
Maurice Nivat

LITP, Université Paris VII, 2 Place Jussieu

75251 Paris-Cedex 05, France

Charles Rattray, BSc, MSc, FIMA, FBCS, C.Eng., C.Math.

Department of Computing Science

University of Stirling, Stirling, FK9 4LA, Scotland, UK

Teodor Rus, $\mathrm{PhD}$

Department of Computer Science

University of Iowa, Iowa City, IA 52242, USA

Giuseppe Scollo, PhD

Fac. Informatica, University of Twente

PO Box 217, NL-7500 AE Enschede, The Netherlands

ISBN-13: 978-3-540-19852-9

e-ISBN-13: 978-1-4471-3227-1

DOI: 10.1007/978-1-4471-3227-1

British Library Cataloguing in Publication Data

Algebraic Methodology and Software Technology (AMAST '93) : Proceedings of the Third Intemational Conference on Algebraic Methodology and Software Technology, University of Twente, The Netherlands, 21-25 June 1993. -

(Workshops in Computing Series)

I. Nivat, Maurice II. Series 005.101512

Library of Congress Cataloging-in-Publication Data

International Conference on Algebraic Methodology and Software

Technology (3rd : 1993 : University of Twente)

Algebraic methodology and software technology (AMAST'91) : proceedings of the Third Intermational Conference on Algebraic Methodology and Software Technology, University of Twente, The Netherlands, 21-25 June 1993 / M. Nivat ... [et al.] (eds.).

p. cm. - (Workshops in computing)

"Published in collaboration with the British Computer Society." Includes bibliographical references and index.

1. Software engineering-Congresses. 2. Abstract data types (Computer science)Congresses. I. Nivat, M. II. British Computer Society. III. Title. IV. Series. QA76.758.I5713 1993

005.1'01'512-dc20

Apart from any fair dealing for the purposes of research or private study, or criticism or review, as permitted under the Copyright, Designs and Patents Act 1988, this publication may only be reproduced, stored or transmitted, in any form, or by any means, with the prior permission in writing of the publishers, or in the case of reprographic reproduction in accordance with the terms of licences issued by the Copyright Licensing Agency. Enquiries conceming reproduction outside those terms should be sent to the publishers.

@British Computer Society 1994

Softcover reprint of the hardcover 1st edition 1994

The use of registered names, trademarks etc. in this publication does not imply, even in the absence of a specific statement, that such names are exempt from the relevant laws and regulations and therefore free for general use.

The publisher makes no representation, express or implied, with regard to the accuracy of the information contained in this book and cannot accept any legal responsibility or liability for any errors or omissions that may be made.

Typesetting: Camera ready by authors

Printed by Antony Rowe Ltd., Chippenham, Wiltshire

34/3830-543210 Printed on acid-free paper 


\section{Preface}

The goal of the AMAST conferences is to foster algebraic methodology as a foundation for software technology, and to show that this can lead to practical mathematical alternatives to the ad-hoc approaches commonly used in software engineering and development. The first two AMAST conferences, held in May 1989 and May 1991 at the University of Iowa, were well received and encouraged the regular organization of further AMAST conferences on a biennial schedule. The third Conference on Algebraic Methodology and Software Technology was held in the campus of the University of Twente, The Netherlands, during the first week of Summer 1993. Nearly a hundred people from all continents attended the conference.

The largest interest received by the AMAST conference among the professionals extended to include the administration organizations as well. AMAST'93 was opened by the Rector of the University of Twente, followed by the Local Chairman. Their opening addresses open this proceedings, too.

The proceedings contains 8 invited papers and 32 selected communications. The selection was very strict, for 121 submissions were received. The topics of the invited papers and selected communications cover both theory and practice, and span a wide variety of algebraic and software development issues, including: algebraic metamathematics, functional programming, relation algebra, order-sorted algebra, category theory in software engineering, modular system design, real-time system specification, testing theory and applications, algebraic semantics of concurrency, process algebra, modal logics and reactive systems, design and refinement principles, object-oriented design and programming, equational and logic programming, algebraic specification in software engineering.

The AMAST goal motivates interest in showcasing software systems that have been developed, or help development, by algebraic methods, techniques and tools. This was materialized in the AMAST'93 programme by seven demonstrations of such systems. One of them relates to the communication by Eric Wagner; short descriptions of the other six systems form the closing part of this proceedings.

In addition to the proceedings, a special issue of the journal Theoretical Computer Science is dedicated to AMAST'93, where some of the selected communications appear in extended form. 
With AMAST'93, besides research, education has taken a distinguished place within the scope of AMAST, and the first conference day, referred to as the Education Day, was devoted to the topic of mathematical education of software developers. Hans-Jörg Kreowski opened the Education Day with an invited talk on Some tentative thoughts on teaching computer science. A lively discussion ensued immediately after his talk. Two sessions then followed, each with an invited talk and an open, informal discussion; conclusions were drawn by Hans-Jörg Kreowski. Yuri Gurevich moderated the morning session on education in which Teodor Rus presented his interpretation of the invited talk Mathematics of computation for (software and other) engineers of David Parnas, prevented from attending the conference by a medical emergency. The conference expressed sympathy and best wishes for a complete recovery to David Parnas. István Németi moderated the afternoon session on education in which Jacques Printz gave an invited talk on Mathematical training for the software developers: a practical experience, based on his extensive professional experience in applying formalism to large software development projects. Space constraints prevent the inclusion of contributions to the Education Day in this proceedings, but the Organizing Committee is exploring avenues to make these available, possibly in refined form to a wide audience.

In continuity with the tradition of the AMAST conferences, very low registration fees were made possible by generous support from the sponsors. The main financial resources were granted by the Commission of the European Communities, within the ESPRIT Basic Research Programme, and by the US Office of Naval Research. Additional financial and organizational support was provided by the universities and institutions represented in the Organizing Committee, and by the British Department of Trade and Industry. The AMAST'93 conference was held under the auspices and with the cooperation of EATCS, ACM SIGACT and SIGSOFT, ASL, BCS FACS, and by the ESPRIT Basic Research working groups ASMICS and COMPASS.

The numerous and well-qualified offers to host future AMAST meetings testify to the interest in the AMAST goals. The fourth AMAST conference will be held at Concordia University, Montréal, Canada, on July 3-7 1995, and will be organized by V.S. Alagar. Then AMAST'96 will follow, at München University, Germany, and will be organized by Martin Wirsing. As can be inferred from this, and in view of the growing number of submissions, the AMAST conference series will become an annual event after AMAST'95. Holding these conferences more frequently will allow a wider recognition of original contributions to the AMAST goals and will give greater opportunities for success in the effort to capture the attention of the entire spread of those working in software engineering.

August 1993

M. Nivat

C. Rattray

T. Rus

G. Scollo 


\section{Organizing Committee}

General chairman:

Maurice Nivat, Université de Paris VII, France

Program chairman:

Giuseppe Scollo, University of Twente, Enschede, The Netherlands

Publicity chairmen:

Charles Rattray, University of Stirling, Scotland

Teodor Rus, University of Iowa, Iowa City, Iowa, USA

V.S. Alagar, Concordia University, Montréal, Quebec, Canada

Education Day chairman:

Hans-Jörg Kreowski, Universität, Bremen, Germany

Local chairman:

Ed Brinksma, University of Twente, Enschede, The Netherlands

Finance chairman:

Frans van der Avert, University of Twente, Enschede, The Netherlands

International Committee:

Mohammed Bettaz, University of Constantine, Algeria

Christine Choppy, Université de Paris-Sud, Orsay, France

Pierre Deransart, INRIA, Rocquencourt, France

Arthur Fleck, University of Iowa, Iowa City, Iowa, USA

Luigi Logrippo, University of Ottawa, Ontario, Canada

Michael O'Donnell, University of Chicago, Illinois, USA

Juan Quemada, University of Madrid, Spain

Ralph Wachter, Office of Naval Research, Arlington, Virginia, USA

Local Committee (University of Twente, Enschede, The Netherlands):

Herman Balsters

Han Bäumer

Pim van den Broek

Rolf de By

Maarten Fokkinga

Pim Kars

Mark van der Voort

Job Zwiers

Secretariat (University of Twente, Enschede, The Netherlands):

Charlotte Bijron, Alice Hoogvliet-Haverkate, Joke Lammerink, Yvonne

Rokker 


\section{Program Committee}

Martin Abadi, DEC, Palo Alto, California, USA

Egidio Astesiano, University of Genova, Italy

Choukry-Bey Ben-Yelles, USTHB, Alger, Algeria

Michel Bidoit, École Normale Superiéure, Paris, France

Wim Blok, University of Illinois, Chicago, Illinois, USA

Chris Brink, University of Cape Town, South Africa

Pierre-Luis Curien, École Normale Superiéure, Paris, France

Kokichi Futatsugi, EL/CLS, Tokyo, Japan

Steven Givant, Mills College, Oakland, California, USA

William S. Hatcher, Université Laval, Quebec City, Canada

Douglas J. Howe, AT\&T, Murray Hill, New Jersey, USA

Bjarni Jónsson, Vanderbilt University, Nashville, Tennessee, USA

Giancarlo Mauri, University of Milano, Italy

Ali Mili, University of Ottawa, Ontario, Canada

Michael Mislove, Tulane University, New Orleans, Louisiana, USA

Ugo Montanari, University of Pisa, Italy

Peter D. Mosses, Aarhus University, Denmark

István Németi, Academy of Sciences, Budapest, Hungary

Don Pigozzi, Iowa State University, Ames, Iowa, USA

Don Sannella, University of Edinburgh, Scotland

R.K. Shyamasundar, Tatra Institute for Fundamental Research, Bombay, India

John Staples, University of Queensland, Brisbane, Australia

Andrzej Tarlecki, Academy of Sciences, Warsaw, Poland

Frits Vaandrager, CWI, Amsterdam, The Netherlands

Paulo A.S. Veloso, Pontificia Universidad Católica, Rio de Janeiro, Brazil

Eric Wagner, IBM, Yorktown Heights, New Jersey, USA

Robert F.C. Walters, University of Sydney, Australia

Martin Wirsing, Universität München, Germany 


\section{Referees}

Besides the members of the Organizing and Program Committees:

$\begin{array}{lll}\text { H. Alblas } & \text { V. Ambriola } & \text { H. Andréka } \\ \text { R. Bagnara } & \text { R.I. Becker } & \text { M. Bellia } \\ \text { L. Bergmans } & \text { J.A. Bergstra } & \text { C. Bettini } \\ \text { A. Blass } & \text { T. Bolognesi } & \text { E. Börger } \\ \text { S. Bruell } & \text { M. Caneve } & \text { F. Cardone } \\ \text { M. Cerioli } & \text { P. Ciancarini } & \text { E. Ciapessoni } \\ \text { H. Comon } & \text { A. Corradini } & \text { P. Degano } \\ \text { R. De Nicola } & \text { J. Desharnais } & \text { H. Eertink } \\ \text { A. Fantechi } & \text { G. Ferrari } & \text { L. Fribourg } \\ \text { H. Garavel } & \text { R.v. Glabbeek } & \text { G. Ghelli } \\ \text { S. Gnesi } & \text { N. Halbwachs } & \text { M. Johnson } \\ \text { S.M. Kahrs } & \text { J.-P. Katoen } & \text { H. Kirchner } \\ \text { R. Langerak } & \text { R.D. Maddux } & \text { A. Maggiolo-Schettini } \\ \text { M.J. Maher } & \text { V. Manca } & \text { M. Maouche } \\ \text { R. Marciano } & \text { S. Martini } & \text { E. Moggi } \\ \text { P. Oude Luttighuis } & \text { C. Palamidessi } & \text { J. Palsberg } \\ \text { F. Parisi-Presicce } & \text { L.C. Paulson } & \text { A. Poigné } \\ \text { V. Pratt } & \text { J. Printz } & \text { G. Reggio } \\ \text { H. Reichel } & \text { A. Rensink } & \text { D. Rosenzweig } \\ \text { F. Rossi } & \text { I. Sain } & \text { A. Salibra } \\ \text { V. Sassone } & \text { S.A. Schneider } & \text { A. Skou } \\ \text { S. Tschantz } & \text { D.A.Wolfram } & \text { H. Zhang } \\ & & \end{array}$




\section{Contents}

Opening Address by the Rector of the University of Twente ............. 1

Welcoming Address AMAST'93 …................................................... 2

\section{Invited Papers}

Applying Algebraic Logic to Logic

H. Andréka, I. Németi and I. Sain .................................................... 5

Relation Algebras for Reasoning About Time and Space

R.D. Maddux

On the Value of Commutative Diagrams in Information Modelling M. Johnson and C.N.G. Dampney

Rigorous Specification of Real-Time Systems

S. Schneider

Full Abstraction in Structural Operational Semantics (Extended

Abstract)

R. van Glabbeek

Synchronous Observers and the Verification of Reactive Systems

N. Halbwachs, F. Lagnier and P. Raymond.

Constraints in Term Algebras (Short Survey)

H. Comon

Joining Abstract and Concrete Computations in Constraint Logic Programming

R. Giacobazzi, G. Levi and S.K. Debray

\section{Communications}

Dimension-Complemented Lambda Abstraction Algebras

D. Pigozzi and A. Salibra

Parameterized Recursion Theory - A Tool for the Systematic Classification of Specification Methods

T. Mossakowski 
Increasing the Level of Abstraction in Traditional Functional Languages by Using Compile-Time Reflection

T. Sheard

A Coherent Type System for a Concurrent, Functional and Imperative Programming Language

D. Bolignano and M. Debabi

Peirce Algebras (Extended Abstract)

C. Brink, K. Britz and R.A. Schmidt

Comparing Two Different Approaches to Products in Abstract

Relation Algebra

R. Berghammer, A. Haeberer, G. Schmidt and P. Veloso

Specifying Type Systems with Multi-Level Order-Sorted Algebra M. Erwig

An Overview of the SODA System

P. Thiemann

Category Theory for the Configuration of Complex Systems

G. Hill

Algebraic-Oriented Institutions

M. Cerioli and G. Reggio

201

On the Correctness of Modular Systems

M. Navarro, F. Orejas and A. Sánchez

Interaction Between Algebraic Specification Grammars and Modular System Design

H. Ehrig and F. Parisi-Presicce

Specification of Hybrid Systems in CRP

R.K. Shyamasundar.

Real-Time Program Synthesis from Specifications

A. Cornell, J. Knaack, A. Nangia and T. Rus

On the Coverage of Partial Validations

E. Brinksma

Verifying Communication Protocols via Testing-Projection

$K$. Drira and P. Azema

Equivalences of Transition Systems in an Algebraic Framework P. Malacaria

Semantics Frameworks for a Class of Modular Algebraic Nets

E. Battiston, V. Crespi, F. De Cindio and G. Mauri

A Characterization of LOTOS Representable Networks of

Parallel Processes

D. de Frutos-Escrig

Towards Performance Evaluation in Process Algebras

R. Gorrieri and M. Roccetti 
Translation Results for Modal Logics of Reactive Systems

F. Laroussinie, S. Pinchinat and Ph. Schnoebelen

Modal Action Logic in a Practical Specification Language

I.N. Kaufman and S.L. Meira

On Using a Composition Principle to Design Parallel Programs

A. Mokkedem and D. Méry

A Notion of Refinement for Automata

N. Sabadini, S. Vigna and R.F.C. Walters

The Role of Memory in Object-Based and Object-Oriented

Languages

E.G. Wagner

Abstract and Concrete Objects - An Algebraic Design Method for Object-Based Systems

R. Breu and M. Breu

Towards an Algebraic Theory of Inheritance in Object

Oriented Programming

X.-M. Lu and T.S. Dillon

An Object-Oriented Design for the ACT ONE Environment M. Gogolla and I. Claßen

A Formal Definition of an Abstract Prolog Compiler (Extended Abstract)

J. Garcia-Martín and J.J. Moreno-Navarro

Completeness of Equational Definitions over Predefined Algebras $V$. Antimirov and A. Degtyarev

An Algebraic Approach to Modeling in Software Engineering G.J. Loegel and C.V. Ravishankar

Automated Proof of the Correctness of a Compiling Specification E.A. Scott

\section{System Demonstrations}

RELVIEW - A Computer System for the Manipulation of Relations

R. Berghammer and G. Schmidt

RALF - A Relation-Algebraic Formula Manipulation System and Proof Checker

C. Hattensperger, R. Berghammer and G. Schmidt

Towards an Integrated Environment for Concurrent Programs Development

N. Brown and D. Méry. 
The LOTOS Toolbox

Th. van der Vloedt.

The ASF + SDF Meta-Environment

A. van Deursen, T.B. Dinesh and E.A. van der Meulen

Executing Action Semantic Descriptions Using ASF + SDF

A. van Deursen and P.D. Mosses..

Author Index. 